\title{
In search for interplay between stool microRNAs, microbiota and short chain fatty acids in Crohn's disease - a preliminary study
}

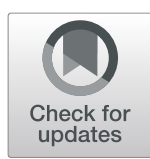

Filip Ambrozkiewicz ${ }^{1 \dagger}$, Jakub Karczmarski ${ }^{1 \dagger}$, Maria Kulecka $^{1,2}$, Agnieszka Paziewska $^{1,2}$, Magdalena Niemira $^{3}$, Natalia Zeber-Lubecka², Edyta Zagorowicz ${ }^{2,4}$, Adam Kretowski ${ }^{3}$ and Jerzy Ostrowski ${ }^{1,2^{*}}$ (1)

\begin{abstract}
Background: Inflammatory bowel diseases are classic polygenic disorders, with genetic loads that reflect immunopathological processes in response to the intestinal microbiota. Herein we performed the multiomics analysis by combining the large scale surveys of gut bacterial community, stool microRNA (miRNA) and short chain fatty acid (SCFA) signatures to correlate their association with the activity of Crohn's disease (CD).

Methods: DNA, miRNA, and metabolites were extracted from stool samples of 15 CD patients, eight with active disease and seven in remission, and nine healthy individuals. Microbial, miRNA and SCFA profiles were assessed using datasets from 16S rRNA sequencing, Nanostring miRNA and GC-MS targeted analysis, respectively.

Results: Pairwise comparisons showed that 9 and 23 taxa differed between controls and CD patients with active and inactive disease, respectively. Six taxa were common to both comparisons, whereas four taxa differed in CD patients. a-Diversity was lower in both CD groups than in controls. The levels of 13 miRNAs differed $(p$-value $<0.05$; FC > 1.5) in CD patients and controls before FDR correction and 4 after. Of six SCFAs, the levels of two differed significantly ( $p$-value $<0.05, F C>1.5$ ) in CD patients and controls, and the levels of four differed in patients with active and inactive CD. PLS-DA revealed models with smallest error rate for controls in bacterial component and inactive disease in metabolites.
\end{abstract}

Conclusion: A complex interrelationship may exist between gut dysbiosis, miRNA profiling and SCFA level in response to intestinal inflammation.

Keywords: Crohn's disease, $16 \mathrm{~S}$ rRNA, miRNA, SCFAs, Biomarker

\section{Background}

Microbial communities of the gastro-intestinal tract consist of at least 100 trillion microorganisms [1, 2]. This complex ecosystem trains the immune system, protects against opportunistic pathogens, harvests nutrients and

\footnotetext{
* Correspondence: jostrow@warman.com.pl

${ }^{\dagger}$ Filip Ambrozkiewicz and Jakub Karczmarski contributed equally to this work. 'Department of Genetics, Maria Sklodowska-Curie National Research Institute of Oncology, Roentgena 5, 02-781 Warsaw, Poland

${ }^{2}$ Department of Gastroenterology, Hepatology and Clinical Oncology, Centre of Postgraduate Medical Education, 02-781 Warsaw, Poland

Full list of author information is available at the end of the article
}

energy from the diet, and ferments non-digestible carbohydrates [3]. A relatively stable composition of gut microbiota within individuals is maintained by diet, sanitation, antibiotics, aging, and other factors [4], commensal microbial compounds promote steady state hematopoiesis, shape-composition, activation status, immune cell repertoires, and vigilance of the innate and adaptive immune systems against different stimuli [5-7].

Infection of the alimentary tract with opportunistic pathogens usually leads to acute gastroenteritis, and disruption of the ecological organization of normal gut

(c) The Author(s). 2020 Open Access This article is licensed under a Creative Commons Attribution 4.0 International License, which permits use, sharing, adaptation, distribution and reproduction in any medium or format, as long as you give appropriate credit to the original author(s) and the source, provide a link to the Creative Commons licence, and indicate if changes were made. The images or other third party material in this article are included in the article's Creative Commons licence, unless indicated otherwise in a credit line to the material. If material is not included in the article's Creative Commons licence and your intended use is not permitted by statutory regulation or exceeds the permitted use, you will need to obtain permission directly from the copyright holder. To view a copy of this licence, visit http://creativecommons.org/licenses/by/4.0/ The Creative Commons Public Domain Dedication waiver (http://creativecommons.org/publicdomain/zero/1.0/) applies to the data made available in this article, unless otherwise stated in a credit line to the data. 
microbiota, called dysbiosis, may lead to immune system defects associated with various chronic human disorders, including the inflammatory bowel diseases (IBDs) Crohn's disease (CD) and ulcerative colitis (UC) $[8,9]$. CD and $\mathrm{UC}$ are classic polygenic disorders, associated with almost 200 risk loci, including more than 30 loci specific for CD [10-12]. These genetic loci were associated with multiple intestinal immunopathological processes that occur in response to intestinal dysbiosis $[10,13]$.

Microbial dysbiosis in IBD is associated with a reduction in bacterial diversity, with colonization by pathogenic bacteria deranging the stability of the entire bacterial community [14]. CD dysbiosis is associated with reductions in Bacteroidetes and Firmicutes, increases in Gammaproteobacteria and Enterobacteriaceae, increases in the isolation of adherent-invasive Escherichia coli from ileal CD biopsies, and reductions in Faecalibacterium prausnitzi commensal, strains of protective bacteria with antiinflammatory properties [15-20].

About $90 \%$ of the total microbial number in adult gut belong to the two most abundant phyla, Bacteroidetes and Firmicutes, which together with Actinobacteria and Verrucomicrobia are the main producers of short chain fatty acids (SCFAs) generated by anaerobic fermentation from dietary carbohydrates (i.e. fiber) and amino acids (i.e. Lglutamate, L-lysine) [21-23]. SCFAs are aliphatic saturated carboxylic acids with acetate, propionate, and butyrate being the most abundant SCFAs in colon and stool [24]. SCFAs are the primary energy source for colonocytes and maintain intestinal homeostasis through its antiinflammatory activities. At the cellular level, SCFAs can influence the proliferation and differentiation of colonic regulatory T-cells (Treg) cells, as well as alter their gene expression [25-27]. The reduced SCFA levels in patients with IBD result from lower abundance of SCFA-producing bacteria, especially those of the phylum Firmicutes [28, 29], but also may relate to reduced fiber consumption. While a long-term intake of dietary fiber has been associated with a lower risk of CD development [30], and a high fiber diet is not harmful and seems to be favorable for CD [31], high fiber consumption is not practically advocated, particularly in the active disease [32].

Micro-RNAs (miRNAs) are small, non-coding particles that play a role in human physiology and pathology, with dysregulated miRNAs contributing to autophagy, intestinal inflammation, and fibrosis [33, 34]. miRNAs, secreted by intestinal epithelial cells, are detected in stool and play a role in crosstalk between microbiota and their hosts [35, 36]. miRNAs can infiltrate bacterial cells, regulate bacterial gene transcription, and promote bacterial growth [36]. miR-223 and miR-1246, which are generally present at high levels in stool, were associated with intestinal inflammation, including in patients with IBD [37], whereas fecal miRNAs may serve as biomarkers of IBD [38].

Although inferring interactions across omics datasets has multiple statistical challenges, the integration of multi-omics datasets pointed the role of microbially produced metabolites and IBD development [39, 40]. However, both IBD host and microbial features that may relate to the gut microbiome should be further characterized, particularly in direct association with the host epithelium and corresponding molecular changes [41].

The aim of this study was to analyze the potential relationship between gut dysbiosis, stool miRNA composition and SCFA level in response to CD intestinal inflammation.

\section{Methods}

Samples

The study cohort consisted of $15 \mathrm{CD}$ patients, five women and ten men, of median age 32 years (range, 2062 years), with adequate clinical information; and nine healthy control individuals, six women and three men, of median age 36 years (range, 26-41 years). CD was diagnosed by experienced gastroenterologists during a standard diagnostic work-up, using the Porto criteria modified in accordance with ECCO guidelines. Patients were recruited during a course of hospital treatment or during a scheduled visit to the out-patient department at the Department of Gastroenterology, Hepatology and Clinical Oncology, Medical Center for Postgraduate Education, Warsaw. Disease activity was determined by measuring the $\mathrm{CD}$ activity index (CDAI) [42], and the $\mathrm{CD}$ patients were assigned to two subgroups. According to the limit for a CDAI score of 220, seven patients in remission or with mild $\mathrm{CD}$ were considered to have inactive disease, and eight patients with moderate to severe $C D$ were considered to have active disease. Most patients had ileocolic inflammation, and their stool samples were collected before medication was administered. Clinical characteristics of the enrolled patients is presented in Table 1. Control individuals, all of whom were hospital employees, reported themselves as being healthy. All enrolled patients and controls were Polish Caucasians.

The study was performed in accordance with the ethical standards of the local bioethical committee and in accordance with the principles of the 1964 Declaration of Helsinki.

\section{Stool collection and preparation}

Subjects were provided a stool collection kit, consisting of a Styrofoam box, tubes, and spatulas for stool samples; an ice pack; and a disposable bag. A stool sample from a single bowel movement was collected and immediately frozen at $-20^{\circ} \mathrm{C}$. Aseptic techniques using a 
Table 1 The clinical characteristics of the enrolled patients;1-Female, 2-Male

\begin{tabular}{|c|c|c|c|c|c|c|}
\hline \multirow[t]{2}{*}{ Sex } & \multirow{2}{*}{$\begin{array}{l}\text { Age } \\
\text { (years) }\end{array}$} & \multirow[t]{2}{*}{ Inflammation } & \multirow{2}{*}{$\begin{array}{l}\mathrm{CD} \\
\text { activity }\end{array}$} & \multicolumn{3}{|l|}{ Previous treatment } \\
\hline & & & & Immunosupressants & Glucocorticoids & Biological therapy \\
\hline 1 & $20-25$ & ileocolonic & active & yes & no & No \\
\hline 2 & $20-25$ & ileocolonic & active & no & yes & No \\
\hline 1 & $30-35$ & colonic & active & no & no & Yes \\
\hline 2 & $45-50$ & ileocolonic & active & no & yes & No \\
\hline 2 & $60-65$ & ileal & active & yes & no & No \\
\hline 2 & $50-55$ & colonic & active & no & no & Yes \\
\hline 2 & $40-45$ & ileocolonic & active & no & no & Yes \\
\hline 1 & $35-40$ & ileocolonic & active & yes & no & No \\
\hline 2 & $30-35$ & ileocolonic & inactive & yes & no & Yes \\
\hline 2 & $30-35$ & ileocolonic & inactive & yes & no & Yes \\
\hline 2 & $30-35$ & ileocolonic & inactive & yes & no & Yes \\
\hline 1 & $35-40$ & ileocolonic & inactive & no & no & Yes \\
\hline 1 & $20-25$ & ileocolonic & inactive & yes & no & Yes \\
\hline 2 & $25-30$ & colonic & inactive & no & no & Yes \\
\hline 2 & $20-25$ & ileocolonic & inactive & yes & no & Yes \\
\hline
\end{tabular}

disposable scalpel were utilized to scrape off approximately 200, 200, and $100 \mathrm{mg}$ of each stool sample for the extraction of DNA, miRNA, and SCFA, respectively.

\section{Fecal DNA extraction and 16S rRNA sequencing}

DNA was extracted from stool samples using QIAamp Fast DNA Stool Mini Kits (Qiagen) according to the manufacturer's directions, except that frozen stool samples, weighing approximately $180 \mathrm{mg}$, were mixed with $1 \mathrm{ml}$ InhibitEx Buffer and incubated at $95^{\circ} \mathrm{C}$ for $5 \mathrm{~min}$ to lyse Gram-positive bacteria. DNA concentrations were measured using a Nanodrop ND-1000 spectrophotometer.

16S rRNA was sequenced on an Ion Torrent Personal Genome Machine (PGM) platform using Ion $\mathrm{PGM}^{\mathrm{Tm}} \mathrm{Hi}$ $\mathrm{Q}^{\text {tw }}$ View OT2 and Ion PGM Hi-Q View Sequencing Kits. 16S rRNA libraries were prepared using Ion $16 \mathrm{~S}$ Metagenomic Kits (which allows a consensus view across 6 regions V2, V3, V4, V6-7, V8 and V9), as previously described [43].

\section{Fecal miRNA extraction and Nanostring nCounter miRNA profiling}

Fecal miRNA was isolated from stool samples (approximately $200 \mathrm{mg}$ ) using mirVana miRNA Isolation Kits, according to the manufacturer's protocol. miRNA was screened using $100 \mathrm{ng}$ miRNA, as recommended, and analyzed with nCounter human v2 miRNA expression assay kits, which allow detection of 800 human miRNAs. Hybridization was performed on the nCounter Prep Station, and miRNA was detected with an nCounter Digital Analyzer.

\section{Short chain fatty acids profiling}

Metabolites were extracted and derivatized as described [44] with modifications. Briefly, frozen stool samples weighing approximately $100 \mathrm{mg}$ were each placed in 2 $\mathrm{ml}$ tubes containing ceramic beads and $1 \mathrm{ml}$ of $10 \%$ isobutanol. The samples were mechanically homogenized twice, for 2 min each, on an HT Lysing Homogenizer at $1500 \mathrm{rpm}$ with a $30 \mathrm{~s}$ interval. The samples were centrifuged at $12000 \mathrm{x} \mathrm{g}$ for $6 \mathrm{~min}$, and $675 \mu \mathrm{l}$ of each supernatant was transferred to a new Eppendorf tube. After adding $125 \mu \mathrm{l}$ of $20 \mathrm{mM} \mathrm{NaOH}$ and $400 \mu \mathrm{l}$ chloroform to each sample, the samples were vortexed and centrifuged at $21000 \mathrm{x} \mathrm{g}$ for $2 \mathrm{~min}$. A $400 \mu \mathrm{l}$ aliquot of each upper aqueous phase was transferred to a new tube; $100 \mu \mathrm{l}$ pyridine and $80 \mu \mathrm{l}$ isobutanol was added; and the volume of each sample was adjusted to $650 \mu$ by adding ultrapure water.

The calibration standards formate, acetate, propionate, butyrate, isobutyrate, and valerate were obtained from Sigma-Aldrich (St. Louis, MO), at the desired concentrations were combined with $125 \mu \mathrm{l}$ of $20 \mathrm{mM} \mathrm{NaOH}$, $100 \mu \mathrm{l}$ pyridine and $80 \mu \mathrm{l}$ isobutanol, and the volume of each was adjusted to $650 \mu \mathrm{l}$ with ultra-pure water.

Samples and calibration standards were derivatized by adding $50 \mu \mathrm{l}$ chloroformate isobutyl to each $650 \mu \mathrm{l} \mathrm{sam-}$ ple. The lid of each tube was opened for $1 \mathrm{~min}$ to release gases produced during the reaction. The samples were vortexed for $1 \mathrm{~min}$, and $170 \mu \mathrm{l}$ hexane was added to each, and the samples were again vortexed. After centrifuging the samples at $20000 \mathrm{xg}$ for $5 \mathrm{~min}$, a $170 \mu \mathrm{l}$ aliquot of each upper Isobutyl-hexane phase was transferred to an autosampler vial. 
SCFAs were quantified by GC/MS on an Agilent 7000D Triple Quadrupole mass spectrometer coupled to a 7890 GC System with a G4513A autosampler and a VF- $5 \mathrm{~ms}$ column $(30 \mathrm{~m}, 0.25 \mathrm{~mm}, 0.50 \mu \mathrm{m})$. The temperatures of the injector, ion source, quadrupole, and transfer line were set at $260^{\circ} \mathrm{C}, 250{ }^{\circ} \mathrm{C}, 150{ }^{\circ} \mathrm{C}$, and $310^{\circ} \mathrm{C}$, respectively. Helium carrier gas flow was maintained at $1 \mathrm{ml} / \mathrm{min}$. A $1 \mu \mathrm{l}$ aliquot of each derivatized sample was injected at a split ratio of $25: 1$, with the solvent delay set at $3 \mathrm{~min}$. The initial column temperature of $40{ }^{\circ} \mathrm{C}$ was maintained for $5 \mathrm{~min}$ and then ramped at a rate of $10^{\circ} \mathrm{C} / \mathrm{min}$ to $310^{\circ} \mathrm{C}$, which was maintained for $10 \mathrm{~min}$. MS data were collected in full scan mode from $\mathrm{m} / \mathrm{z}$ 15300 at a frequency of 4 scans per second. The target ion $(\mathrm{m} / \mathrm{z})$ of formate, acetate, propionate, isobutyrate, butyrate, and valerate were $56,56,57,71,71$, and 85 , respectively.

\section{Statistical analysis 16S rRNA analysis}

Unmapped BAM files were converted to FASTQ using Picard's [45] SamToFastq. Additional steps of the analysis were performed using Mothur [46] version 1.38 software. FASTQ files were converted to the FASTA format. For analyses, only the sequences that were 200-300 bases in length, with an average base quality of 20 in a sliding window of 50 bases, and a maximum homopolymer length of 10 were kept. Chimeric sequences were identified with the UCHIME [47] algorithm using default parameters, with internal sequence collection as the reference database. Chimeric sequences were removed, and the remaining $16 \mathrm{~S}$ rRNA sequences were classified using the Wang method and the SILVA [48] bacterial $16 \mathrm{~S}$ rRNA database for reference (release 132), at an $80 \%$ bootstrap cut-off. The non-parametric Shannon diversity index and the Chao richness index were determined with Mothur. Differences in taxa prevalence were determined with Fisher's exact test corrected with BenjaminiHochberg procedure. Between group differences in the abundance of taxa were assessed with DESeq2 [49], using Wald's test to determine the statistical significance of fold-change difference The default DESeq2 normalization (based on median of ratios) and dispersion estimations were applied. The normalization and dispersion estimations were counted for the whole dataset and appropriate comparisons were extracted with DESeq2 contrast option. The $p$-values were then adjusted for multiple testing with Benjamini-Hochberg procedure. Taxa with median normalized count value smaller than 5 in both groups or taxa with adjusted pvalue in Fisher's exact test for prevalence smaller than 0.05 were excluded from analysis. Differences in diversity indices values were assessed using the Kruskall-Wallis test, followed by the post-hoc Mann-Whitney U-test.

\section{miRNA analysis}

Data were processed and analyzed with nSolver ${ }^{\mathrm{Tm}}$ Analysis Software 4.0. Levels of expression were normalized relative to the geometric mean of the 100 miRNAs with the highest numbers of counts. Due to counts of negative probes, all results were corrected using a background threshold value set at 40 counts. Significant differences were determined by $t$-tests. miRNA was considered differentially expressed when FC $>1.5$ and corrected $p$-value $<0.05$ (Benjamini-Hochberg algorithm).

\section{SCFA analysis}

Data were analyzed by MassHunter software. SCFA concentrations were obtained from calibration curve. SCFA values were $\log 10$ transformed. Significant differences were determined by ANOVA test.

\section{Integrated analysis}

Taxonomic, miRNA, and metabolite data (including Partial Least Squares Discriminant Analysis (PLS -DA) were integrated using the DIABLO function of the MixOmics [50] package. The numbers of components and variables were tuned according to the tutorial present at http://mixomics.org/mixdiablo/case-studytcga/. The number of components was determined after M-fold cross-validation (with 5 folds and 100 repeats) performance assessment of full PLS model, using the number given by Weighted Prediction for error rate. The number of variables in each component was determined with mixOmics tune.block.splsda function with the same validation method as above and distances between centroids as distance measure. Final model performance was assessed with M-fold cross-validation with 5 folds and 1000 repeats. The correlation between variables relevant both in integrated models and statistically significant in previous tests was determined with Spearman's coefficient. Multiple testing correction for corresponding $p$-values for coefficients was performed with FDR procedure.

\section{Results \\ 16S rRNA microbiome survey}

An average of 92,000 reads were generated (minimum 57,808 , maximum - 145,096), fulfilling the quality criteria, described in Materials and Methods. Of the 432 taxa identified in these samples, 81 were present at level higher than $0.1 \%$ of reads. The five most abundant bacterial families were Bacteroidaceae, Burkholderiaceae, Ruminococcaceae, Lachnospiraceae, and Prevotellaceae.

In pairwise comparisons, 9 and 23 taxa abundances differentiated healthy controls and CD patients with active and inactive disease, respectively (Fig. 1). When controls were compared with patients with active disease, Enterobacteriaceae, including genus Escherichia-Shigella 


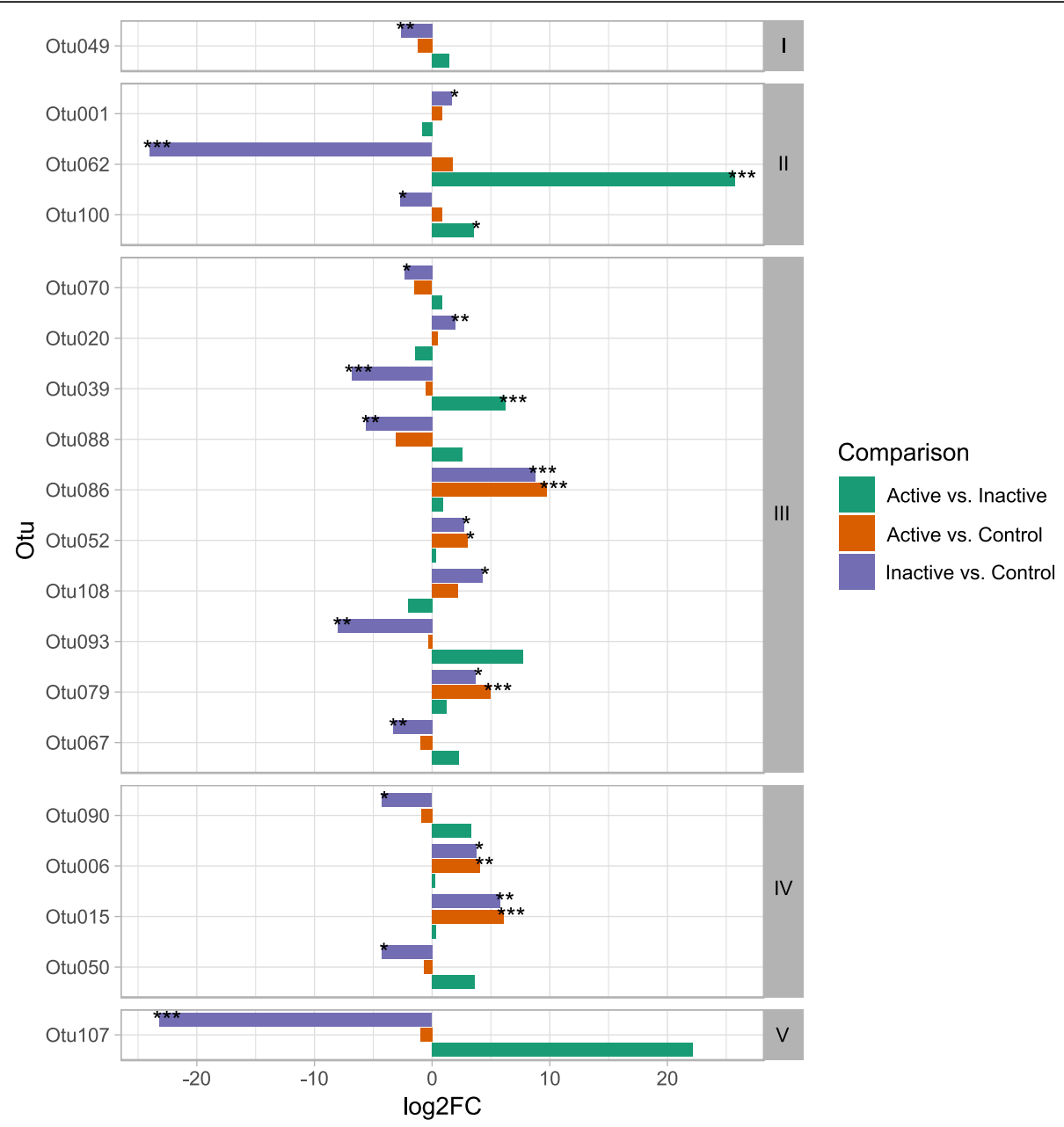

Fig. 1 Statistically significant taxonomic changes occurring in at least one comparison of control subjects, patients with inactive CD, and patients with active CD; Phyla: I - Bacteria unclassified, II - Bacteroidetes, III - Firmicutes, IV - Proteobacteria, V - Verrucomicrobia; $P$-value: ${ }^{*}<0.05$, ** $<$ $0.01,{ }^{* * *}<0.001$

and Lachnospiraceae, including Tyzerella_4 were overrepresented. Similar bacteria were over-represented in patients with inactive CD. In addition, Bacteroides were over-represented, whereas Pasteurellaceae and the genus Coprobacter were under-represented, in patients with inactive CD. Overall, six taxa (including Enterobacteriaceae, Escherichia-Shigella, Tyzzerella_4, Erysipelotrichaceae_ genus, Erysipelatoclostridium, and Flavonifractor) differed in healthy controls and both groups of $\mathrm{CD}$ patients (Table 2, Supplementary Tables S1 and S2).

In addition, the levels of four taxa differed in patients with active and inactive $\mathrm{CD}$, with Coprobacter showing the greatest difference (Supplementary Table S3). All differences are present after Benjamini - Hochberg procedure multiple testing correction.

Compared with controls, both groups of CD patients showed lower alpha diversity (Kruskall-Wallis test, $p$ value $=0.01$ for Np Shannon index; Fig. 2). There were no significant differences, however, in species richness.

\section{miRNA profiling}

Stool miRNA profiles in the CD subgroups and healthy controls were determined by Nanostring screening, which allowed detection of 800 human miRNA, with 149 miRNAs above the threshold, which had been set at 40 counts.

Before multiple testing correction, levels of $13 \mathrm{miR}$ NAs significantly differed (FC $>1.5$ and $p$-value $<0.05$ ) $\mathrm{CD}$ patients from controls. Of these, four (hsa-miR-2233p, hsa-miR-142-3p, hsa-miR-16-5p, and hsa-miR-23a$3 p)$ were more abundant in patients with $C D$, and nine (hsa-miR-577, hsa-miR-379-5p, hsa-miR-642a-3p, hsamiR-26b-5p, hsa-miR-361-5p, hsa-miR-194-5p, hsa-miR202-3p, hsa-miR-155-5p, and hsa-miR-141-3p) were less abundant in CD patients (Table 3). After multiple test correction with the Benjamini - Hochberg procedure, four miRNAs (hsa-miR-577, hsa-miR-379-5p, hsa-miR642a-3p, hsa-miR-26b-5p) remained differential; all of them were less abundant in patients with $\mathrm{CD}$. 
Table 2 Taxa differing between healthy controls and patients with active and inactive CD

\begin{tabular}{|c|c|c|c|c|}
\hline Otu & $\log 2 \mathrm{FC}$ & padj & Taxonomy & Comparison \\
\hline Otu086 & 9.73 & 8.05E-05 & $\begin{array}{l}\text { Bacteria;Firmicutes;Clostridia;Clostridiales;Lachnospiraceae; } \\
\text { Tyzzerella_4; }\end{array}$ & CONTROL vs Active \\
\hline Otu114 & 6.46 & $3.16 \mathrm{E}-04$ & $\begin{array}{l}\text { Bacteria;Firmicutes;Erysipelotrichia;Erysipelotrichales; } \\
\text { Erysipelotrichaceae;Erysipelotrichaceae_ge; }\end{array}$ & CONTROL vs Active \\
\hline Otu015 & 6.09 & $5.21 \mathrm{E}-04$ & $\begin{array}{l}\text { Bacteria;Proteobacteria;Gammaproteobacteria;Enterobacteriales; } \\
\text { Enterobacteriaceae;Escherichia-Shigella; }\end{array}$ & CONTROL vs Active \\
\hline Otu079 & 4.98 & $5.28 \mathrm{E}-04$ & $\begin{array}{l}\text { Bacteria;Firmicutes;Erysipelotrichia;Erysipelotrichales; } \\
\text { Erysipelotrichaceae;Erysipelatoclostridium; }\end{array}$ & CONTROL vs Active \\
\hline Otu123 & 3.74 & $2.51 \mathrm{E}-03$ & $\begin{array}{l}\text { Bacteria;Firmicutes;Clostridia;Clostridiales;Ruminococcaceae; } \\
\text { Anaerotruncus; }\end{array}$ & CONTROL vs Active \\
\hline Otu006 & 4.04 & 7.36E-03 & $\begin{array}{l}\text { Bacteria;Proteobacteria;Gammaproteobacteria;Enterobacteriales; } \\
\text { Enterobacteriaceae; }\end{array}$ & CONTROL vs Active \\
\hline Otu156 & 6.31 & $1.47 \mathrm{E}-02$ & $\begin{array}{l}\text { Bacteria;Firmicutes;Clostridia;Clostridiales;Lachnospiraceae; } \\
\text { Hungatella; }\end{array}$ & CONTROL vs Active \\
\hline Otu052 & 3.06 & $1.85 \mathrm{E}-02$ & $\begin{array}{l}\text { Bacteria;Firmicutes;Clostridia;Clostridiales;Ruminococcaceae; } \\
\text { Flavonifractor; }\end{array}$ & CONTROL vs Active \\
\hline Otu205 & -3.69 & $1.85 \mathrm{E}-02$ & $\begin{array}{l}\text { Bacteria;Firmicutes;Clostridia;Clostridiales;Lachnospiraceae; } \\
\text { Lachnospiraceae_UCG-008; }\end{array}$ & CONTROL vs Active \\
\hline Otu062 & -23.98 & $2.91 \mathrm{E}-27$ & $\begin{array}{l}\text { Bacteria;Bacteroidetes;Bacteroidia;Bacteroidales;Barnesiellaceae; } \\
\text { Coprobacter; }\end{array}$ & CONTROL vs Inactive \\
\hline Otu107 & -23.16 & 1.80E-14 & $\begin{array}{l}\text { Bacteria;Verrucomicrobia;Verrucomicrobiae;Verrucomicrobiales; } \\
\text { Akkermansiaceae;Akkermansia; }\end{array}$ & CONTROL vs Inactive \\
\hline Otu039 & -6.86 & $3.92 \mathrm{E}-05$ & $\begin{array}{l}\text { Bacteria;Firmicutes;Clostridia;Clostridiales;Lachnospiraceae; } \\
\text { Lachnospiraceae_NK4A136_group; }\end{array}$ & CONTROL vs Inactive \\
\hline Otu086 & 8.79 & 4.34E-04 & $\begin{array}{l}\text { Bacteria;Firmicutes;Clostridia;Clostridiales;Lachnospiraceae; } \\
\text { Tyzzerella_4; }\end{array}$ & CONTROL vs Inactive \\
\hline Otu015 & 5.78 & $1.38 \mathrm{E}-03$ & $\begin{array}{l}\text { Bacteria;Proteobacteria;Gammaproteobacteria;Enterobacteriales; } \\
\text { Enterobacteriaceae;Escherichia-Shigella; }\end{array}$ & CONTROL vs Inactive \\
\hline Otu020 & 1.97 & $1.38 \mathrm{E}-03$ & Bacteria;Firmicutes;Clostridia;Clostridiales;Lachnospiraceae;Blautia; & CONTROL vs Inactive \\
\hline Otu114 & 5.79 & $1.38 \mathrm{E}-03$ & $\begin{array}{l}\text { Bacteria;Firmicutes;Erysipelotrichia;Erysipelotrichales; } \\
\text { Erysipelotrichaceae;Erysipelotrichaceae_ge; }\end{array}$ & CONTROL vs Inactive \\
\hline Otu067 & -3.29 & $2.20 \mathrm{E}-03$ & $\begin{array}{l}\text { Bacteria;Firmicutes;Firmicutes_unclassified;Firmicutes_unclassified; } \\
\text { Firmicutes_unclassified; }\end{array}$ & CONTROL vs Inactive \\
\hline Otu120 & -3.90 & 3.45E-03 & $\begin{array}{l}\text { Bacteria;Firmicutes;Clostridia;Clostridiales;Family_ } \\
\text { XIII;Family_XIII_AD3011_group; }\end{array}$ & CONTROL vs Inactive \\
\hline Otu049 & -2.68 & $5.36 \mathrm{E}-03$ & $\begin{array}{l}\text { Bacteria;Bacteria_unclassified;Bacteria_unclassified; } \\
\text { Bacteria_unclassified;Bacteria_unclassified; }\end{array}$ & CONTROL vs Inactive \\
\hline Otu093 & -8.06 & 5.36E-03 & $\begin{array}{l}\text { Bacteria;Firmicutes;Clostridia;Clostridiales;Ruminococcaceae; } \\
\text { Ruminococcaceae_UCG-014; }\end{array}$ & CONTROL vs Inactive \\
\hline Otu088 & -5.64 & $6.05 E-03$ & $\begin{array}{l}\text { Bacteria;Firmicutes;Clostridia;Clostridiales;Lachnospiraceae; } \\
\text { Lachnospiraceae_UCG-001; }\end{array}$ & CONTROL vs Inactive \\
\hline Otu006 & 3.80 & 1.19E-02 & $\begin{array}{l}\text { Bacteria;Proteobacteria;Gammaproteobacteria;Enterobacteriales; } \\
\text { Enterobacteriaceae; }\end{array}$ & CONTROL vs Inactive \\
\hline Otu079 & 3.72 & $1.72 \mathrm{E}-02$ & $\begin{array}{l}\text { Bacteria;Firmicutes;Erysipelotrichia;Erysipelotrichales; } \\
\text { Erysipelotrichaceae;Erysipelatoclostridium; }\end{array}$ & CONTROL vs Inactive \\
\hline Otu001 & 1.70 & 2.07E-02 & $\begin{array}{l}\text { Bacteria;Bacteroidetes;Bacteroidia;Bacteroidales;Bacteroidaceae; } \\
\text { Bacteroides; }\end{array}$ & CONTROL vs Inactive \\
\hline Otu090 & -4.26 & 2.07E-02 & $\begin{array}{l}\text { Bacteria;Proteobacteria;Deltaproteobacteria;Desulfovibrionales; } \\
\text { Desulfovibrionaceae; }\end{array}$ & CONTROL vs Inactive \\
\hline Otu108 & 4.30 & 2.07E-02 & $\begin{array}{l}\text { Bacteria;Firmicutes;Clostridia;Clostridiales;Ruminococcaceae; } \\
\text { Oscillospira; }\end{array}$ & CONTROL vs Inactive \\
\hline Otu070 & -2.36 & $2.87 \mathrm{E}-02$ & $\begin{array}{l}\text { Bacteria;Firmicutes;Clostridia;Clostridiales; } \\
\text { Clostridiales_unclassified; }\end{array}$ & CONTROL vs Inactive \\
\hline
\end{tabular}


Table 2 Taxa differing between healthy controls and patients with active and inactive CD (Continued)

\begin{tabular}{lllll}
\hline Otu & log2FC & padj & Taxonomy & Comparison \\
\hline Otu118 & -2.97 & $2.87 \mathrm{E}-02$ & $\begin{array}{l}\text { Bacteria;Firmicutes;Clostridia;Clostridiales;Ruminococcaceae; } \\
\text { Ruminococcaceae_UCG-013; }\end{array}$ & CONTROL vs Inactive \\
Otu050 & -4.30 & $3.28 \mathrm{E}-02$ & $\begin{array}{l}\text { Bacteria;Proteobacteria;Gammaproteobacteria;Pasteurellales; } \\
\text { Pasteurellaceae; }\end{array}$ & CONTROL vs Inactive \\
Otu052 & 2.70 & $3.62 \mathrm{E}-02$ & $\begin{array}{l}\text { Bacteria;Firmicutes;Clostridia;Clostridiales;Ruminococcaceae; } \\
\text { Flavonifractor; }\end{array}$ & CONTROL vs Inactive \\
Otu100 & -2.69 & $4.95 \mathrm{E}-02$ & $\begin{array}{l}\text { Bacteria;Bacteroidetes;Bacteroidia;Bacteroidia_unclassified; } \\
\text { Bacteroidia_unclassified; }\end{array}$ & CONTROL vs Inactive \\
Otu163 & 4.87 & $4.95 \mathrm{E}-02$ & $\begin{array}{l}\text { Bacteria;Firmicutes;Erysipelotrichia;Erysipelotrichales; } \\
\text { Erysipelotrichaceae;Faecalitalea; }\end{array}$ & CONTROL vs Inactive
\end{tabular}

(Abbreviations: Otu Taxon number, log2FC base 2 logarithm of fold difference between groups, padj FDR-adjusted p-value derived from DESEQ2 results, taxonomy Taxonomic classification, comparison groups showing a difference in that taxon)

In addition, the levels of 12 miRNAs differed significantly in stool samples from patients with active disease and healthy controls, with five being more abundant and seven being less abundant in patients with active $C D$. After multiple testing correction, three of them (hsa-miR379-5p, hsa-miR-577, hsa-miR-26b-5p), all less abundant in patients with $\mathrm{CD}$, remained differential (Table 4).

Moreover, the levels of seven miRNAs differed significantly in stool samples from patients with inactive disease and healthy controls, with all seven being more abundant in patients with inactive CD (Table 5). The levels of two miRNA (hsa-miR-1246 and hsa-miR-4488) differed significantly in patients with active and inactive CD (Table 6). In both cases they turned out statistically insignificant after multiple test correction.

\section{SCFA profiling}

To test for significant association between $C D$ status and SCFAs, the levels of six SCFAs (formate, acetate, propionate, isobutyrate, butyrate and valerate) were measured in stool extracts of patients with active $C D$, inactive $\mathrm{CD}$, and controls. ANOVA showed significant differences in SCFA levels among these three groups (Fig. 3 and Supplementary Table S4).

Of the six SCFAs assayed, two, butyrate and valerate, differed significantly ( $p$-value $<0.05, \mathrm{FC}>1.5$ ) in CD patients and healthy controls. Although none of these SCFAs differed between patients with active disease and controls, three differed significantly in patients with inactive disease and controls, and four differed significantly in patients with active and inactive CD (Table 7).

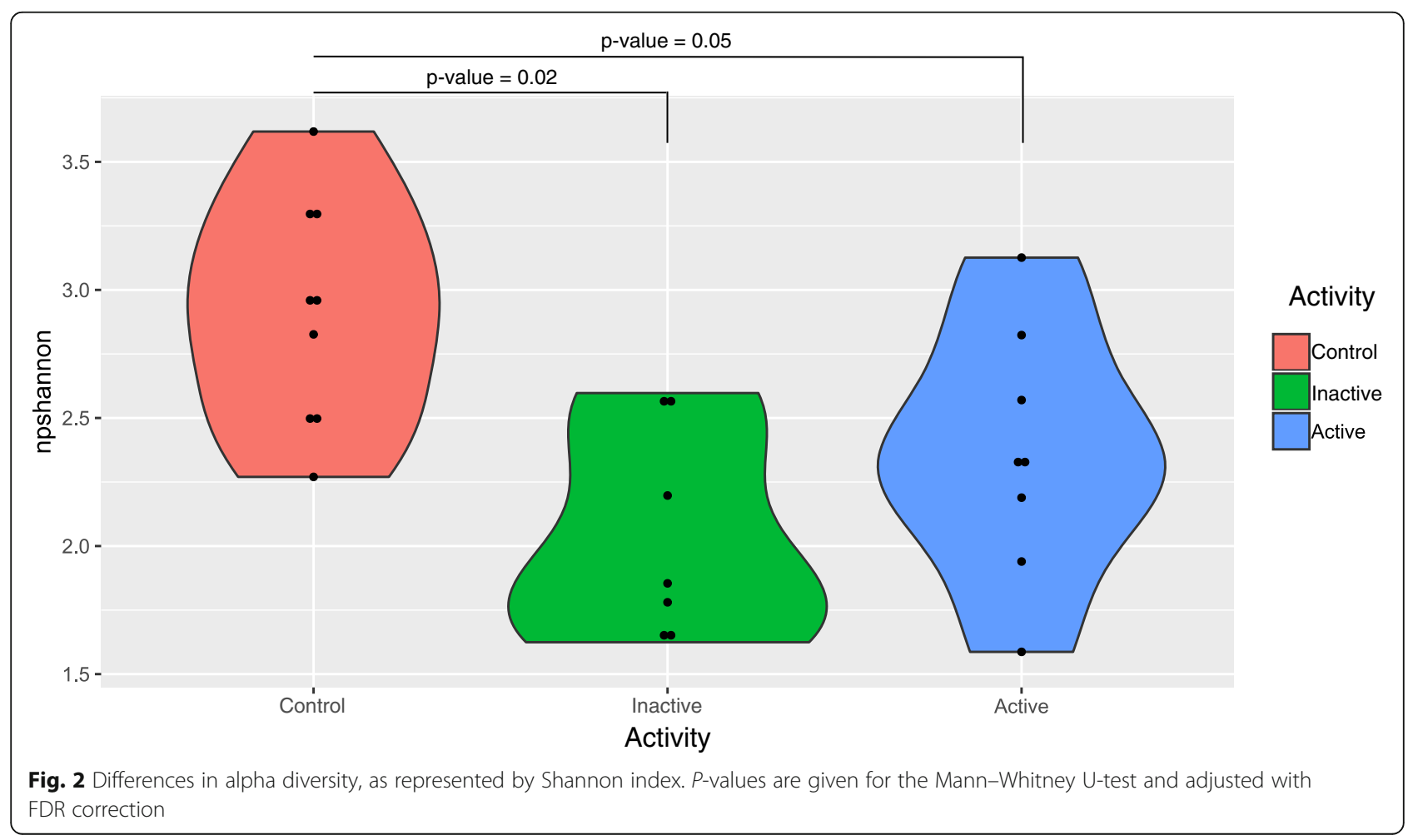




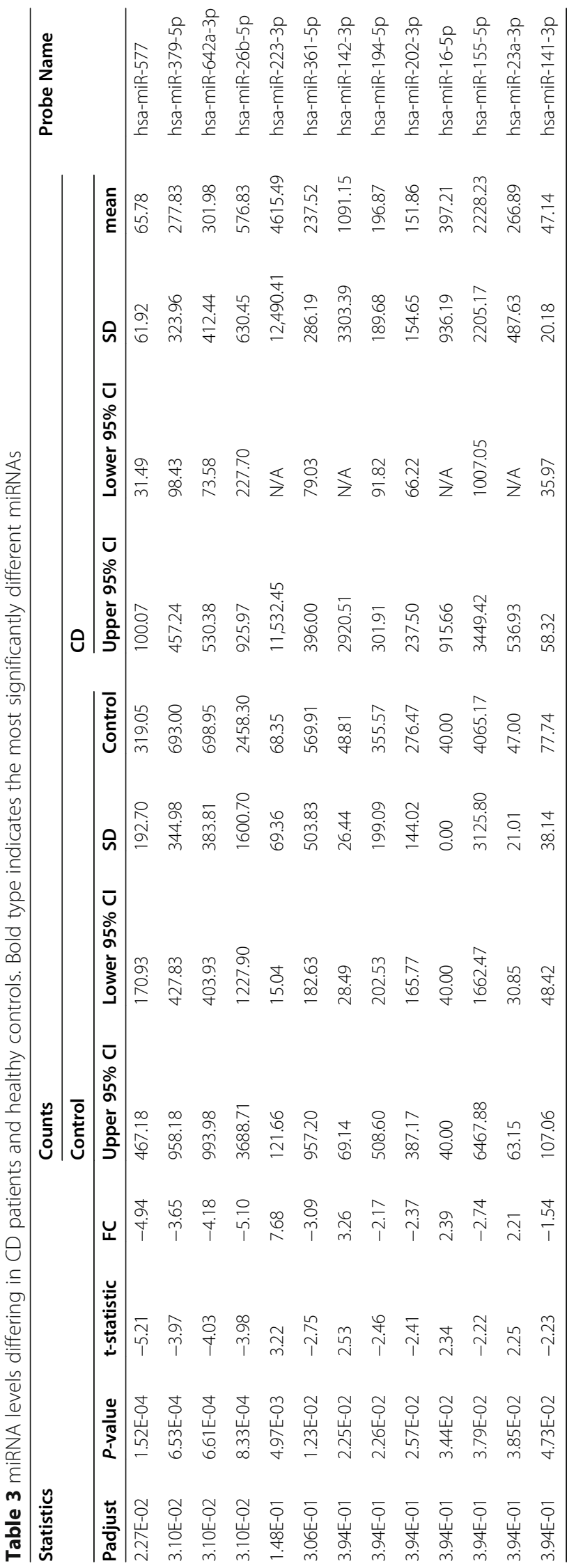




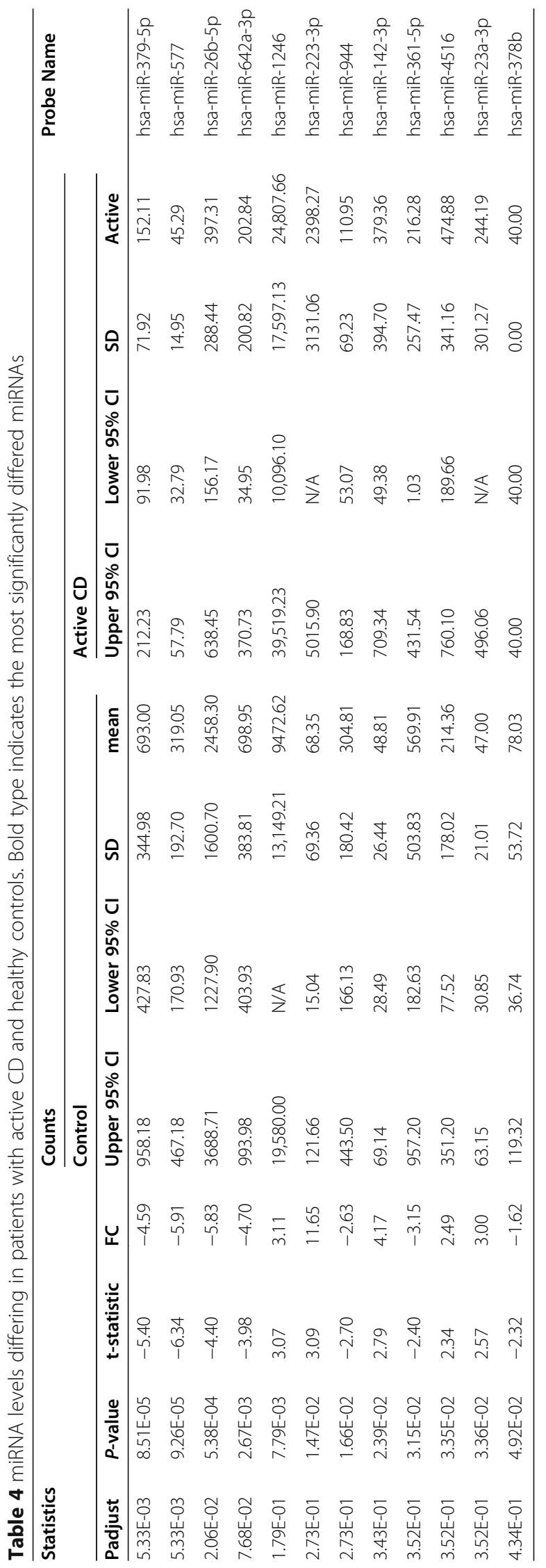




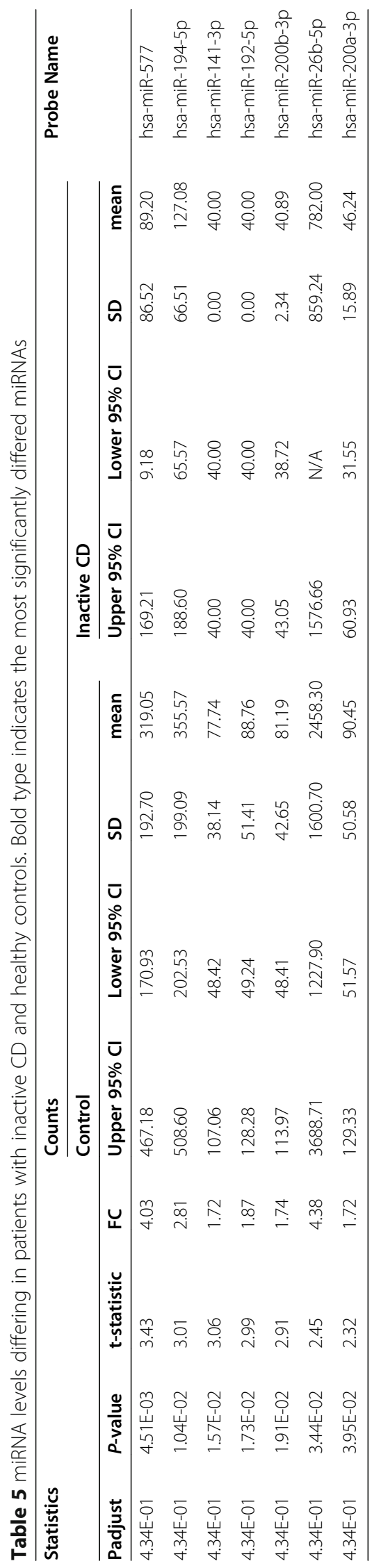




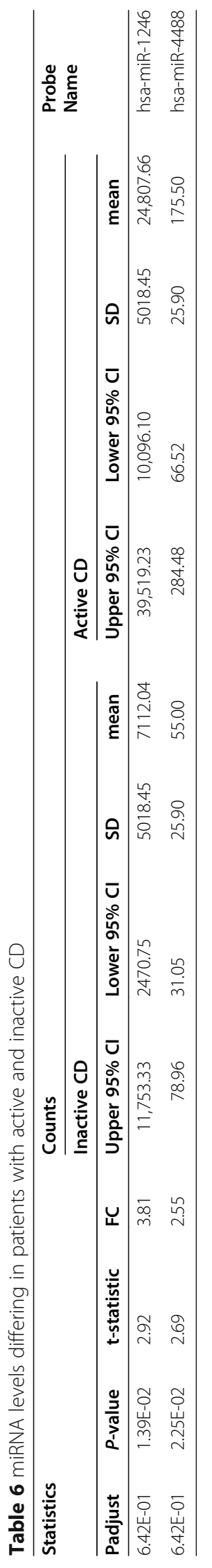




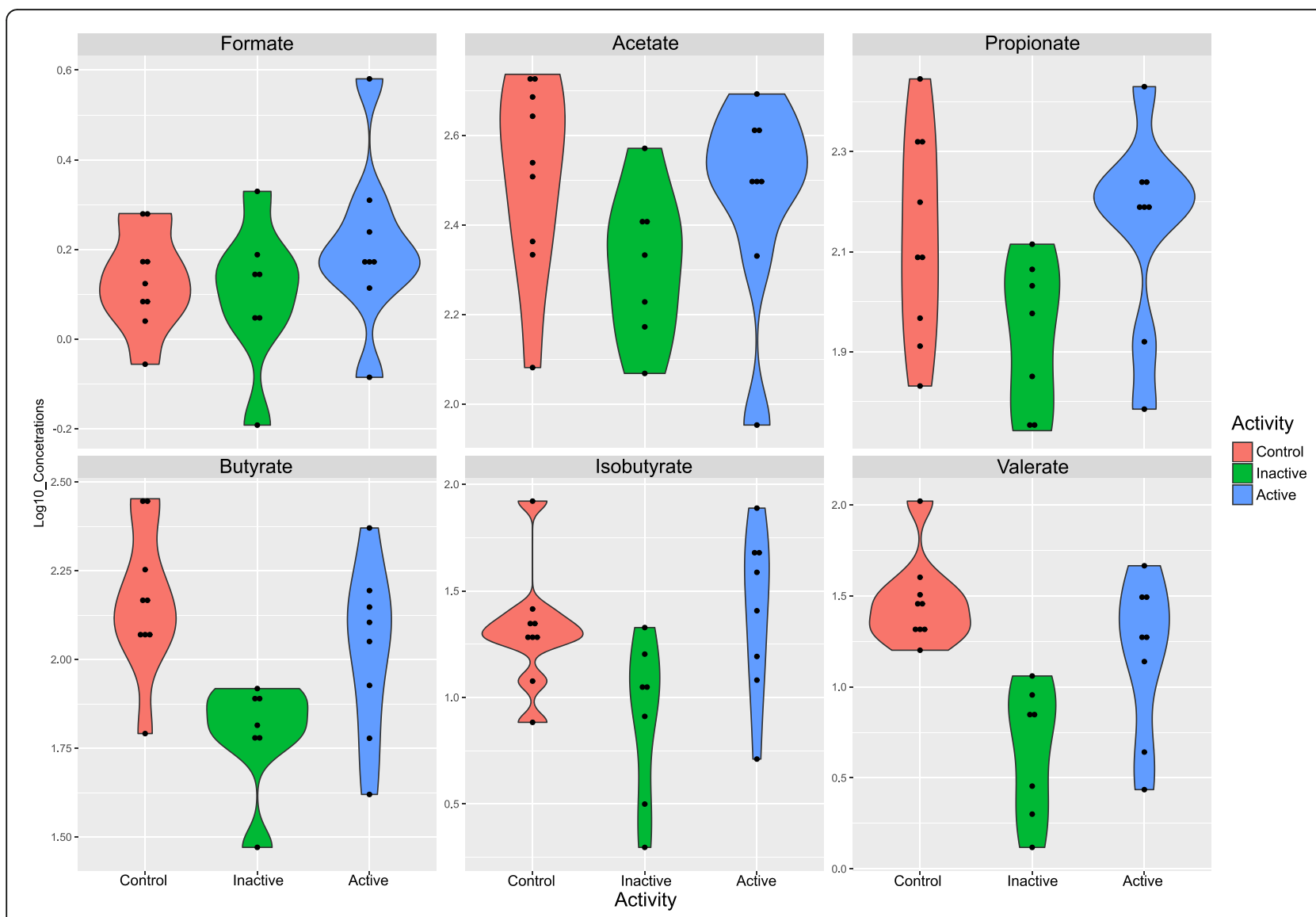

Fig. 3 SCFA concentrations differing significantly in patients with active $C D$, inactive $C D$, and healthy controls

\section{Integrated analysis}

Partial Least Squares Discriminant Analysis (PLS-DA) (Fig. 4) identified models with smallest error rate for controls in bacteria (16\% in the first component) and for inactive disease in metabolites $(2 \%$ in the first component). Active $\mathrm{CD}$ cases showed a high level of error for all surveys, reaching the lowest level in the $16 \mathrm{~S}$ rRNA sequencing survey. Model tuning resulted in a multi-omics biomarker panel with two components, including 15 bacterial taxa, five miRNAs, and five metabolites in both components. Of the 25 variables in the first component, 16 were influential in differentiating healthy controls from other outcomes, whereas the variables included in the second component were able to differentiate between patients with active and inactive CD (Supplementary Figure F1 and Supplementary Table S5).

Eleven correlations with high $(>0.6)$ values of Spearman's coefficient were observed between variables that were either a part of final PLS-DA model or differentiated healthy controls from patients in the previous comparisons. However, none of them reached statistical significance after multiple testing correction (Supplementary Table S6).

\section{Discussion}

Gut dysbiosis may be involved in the development of inflammatory disorders, including IBDs, type 1 diabetes, allergy, asthma, rheumatoid arthritis, and neurological diseases [51, 52]. In animal models of intestinal inflammation, dysbiosis initiated by acute pathogenic infection was associated with an impact on gut immune system that promoted chronic gut inflammation [53-55]. Despite UC and CD sharing many epidemiologic, immunologic, therapeutic, and clinical features, assessments of the microbiomes of patients with the respective diseases showed that they are two distinct subtypes of IBDs [56]. Although dysbiosis may play a major role in the pathogenesis of $\mathrm{CD}$, it likely plays a much lesser role in the pathogenesis of UC $[57,58]$.

This study assessed the profiles of fecal microbiomes, SCFAs, and miRNAs in CD patients with active and inactive disease and in healthy controls. On the microbial level, we confirmed the occurrence of dysbiosis in CD patients, with these patients having lower $\alpha$-diversity than healthy individuals, a finding in agreement with previous results [56]. Patients with inactive CD presented lower $\alpha$-diversity than patients with active $C D$. This may be a result of a bacterial overgrowth, common 
Table 7 SCFA levels differing significantly in patients with active CD, inactive CD, and healthy controls

\begin{tabular}{|c|c|c|c|c|c|c|c|}
\hline SCFA & & Formate & Acetate & Propionate & Butyrate & Isobutyrate & Valerate \\
\hline \multirow[t]{2}{*}{ CD patients vs. Control } & $p$-value & $6.79 \mathrm{E}-01$ & 2.01E-01 & $3.59 \mathrm{E}-01$ & $1.45 \mathrm{E}-02$ & 4.00E-01 & $4.78 \mathrm{E}-03$ \\
\hline & FC & 0.89 & 1.31 & 1.20 & 1.71 & 1.12 & 2.51 \\
\hline \multirow[t]{2}{*}{ Active CD vs. Control } & $p$-value & 3.06E-01 & $6.59 \mathrm{E}-01$ & $8.57 \mathrm{E}-01$ & $2.15 \mathrm{E}-01$ & 5.91E-01 & 1.03E-01 \\
\hline & FC & 0.79 & 1.12 & 0.97 & 1.34 & 0.76 & 1.66 \\
\hline \multirow[t]{2}{*}{ Inactive CD vs. Control } & $p$-value & 6.67E-01 & $6.61 \mathrm{E}-02$ & 5.47E-02 & $1.29 \mathrm{E}-03$ & $2.54 \mathrm{E}-02$ & 9.67E-05 \\
\hline & FC & 1.04 & 1.64 & 1.65 & 2.48 & 2.46 & 5.96 \\
\hline \multirow[t]{2}{*}{ Active $C D$ vs. Inactive $C D$} & $p$-value & $2.59 \mathrm{E}-01$ & $1.82 \mathrm{E}-01$ & $3.90 \mathrm{E}-02$ & 4.70E-02 & $2.55 \mathrm{E}-02$ & $2.55 \mathrm{E}-02$ \\
\hline & FC & 0.75 & 0.68 & 0.59 & 0.54 & 0.31 & 0.28 \\
\hline \multirow[t]{3}{*}{ Control } & mean & 0.13 & 2.51 & 2.13 & 2.16 & 1.31 & 1.47 \\
\hline & median & 0.12 & 2.54 & 2.09 & 2.16 & 1.30 & 1.44 \\
\hline & StDev & 0.11 & 0.22 & 0.21 & 0.20 & 0.28 & 0.24 \\
\hline \multirow[t]{3}{*}{ Inactive } & mean & 0.10 & 2.31 & 1.94 & 1.79 & 0.90 & 0.65 \\
\hline & median & 0.14 & 2.33 & 1.98 & 1.81 & 1.04 & 0.84 \\
\hline & StDev & 0.16 & 0.17 & 0.15 & 0.15 & 0.38 & 0.36 \\
\hline \multirow[t]{3}{*}{ Active } & mean & 0.21 & 2.46 & 2.15 & 2.02 & 1.40 & 1.18 \\
\hline & median & 0.18 & 2.51 & 2.20 & 2.08 & 1.50 & 1.27 \\
\hline & StDev & 0.19 & 0.23 & 0.20 & 0.24 & 0.39 & 0.43 \\
\hline
\end{tabular}

in $\mathrm{CD}$ [59]. The abudance of Bacteroidetes were higher, whereas the amounts of Firmicutes were lower, in stool samples from $\mathrm{CD}$ patients than from controls. While Bacteroidetes are usually commensal species, they can induce the IBD in mouse models [60]; they also benefit hosts by being the main producers of butyrate [61]. A comprehensive overview of functional dysbiosis in the gut microbiome during IBD activity showed increases in facultative anaerobes, such as E. coli which correlates with inflammation status [17, 62], and decreases in obligate anaerobes, such as Faecalibacterium prausnitzii and Roseburia hominis [41]. Adult CD patients naïve to active treatment showed reductions in Firmicutes and Clostridia, and increases in Bacteroidetes [63]. A combination of 50 fecal bacterial taxa was recently shown to distinguish between active $\mathrm{CD}$ and $\mathrm{CD}$ in remission, with an AUC of 0.82, and the discriminatory power of the model was not influenced by disease locations and medications [64]. In sum, the bacterial community may reflect the CD status [58]. However, we could not relate the results to the patient's bowel movement due to the lack of Bristol stool scale data.

The results of the present study confirmed decreases in the abundance of Firmicutes and Bacteroidetes, increases in Enterobacteriaceae, Pasteurellaceae, and Veillonellaceae and the presence of Fusobacterium in stool samples of $C D$ patients $[65,66]$. The distinguishing taxa, including Lachnospiraceae, Ruminococcus, Roseburia, Blautia, F. prausnitzii and B. fragilis, had been previously found as associating with disease activity in $C D$ patients [67-71]. ,Although several studies showed that F. prausnitzii was decreased in the feces and intestinal tissues in patients with active CD [19, 67, 72], other studies found that F. prausnitzii was associated with remission [64]; however these findings were not confirmed in our study. An abundance of $B$. fragilis could distinguish between patients in remission and those with active disease [73, 74].

Gut microbiota, which live in a nutrient-rich environment, are involved in nutrient processing and maintaining energy homeostasis of the host [27, 57]. These bacteria also modulate the development of gutassociated lymphoid tissue and the colonization of the gut wall by intraepithelial lymphocytes, neutrophils, dendritic cells, ILC3s, mucosal-associated invariant Tcells, TCR $\alpha \beta$ Th17 cells, TCR $\gamma \delta$ IL-17-producing cells, Tregs, and immunoglobulin (Ig) A secreting plasma cells [57]. Microbiota also protect the host from opportunistic pathogens $[75,76]$ by producing bacteriocins and SCFAs. SCFAs show crosstalk with the intestinal barrier by stimulating mucus production by epithelial cells and the rearrangement of tight junction proteins, and with the systemic immune system after translocation from the gut to the bloodstream [77-79]. Differences between individuals with and without IBDs were most apparent in the metabolome showing a lower diversity of metabolite pools in IBD patients, a lower diversity that may be caused by poor nutrient absorption, greater water or blood content in the bowels, and shorter bowel transit times in individuals with active IBD [41]). IBD gut dysbiosis 


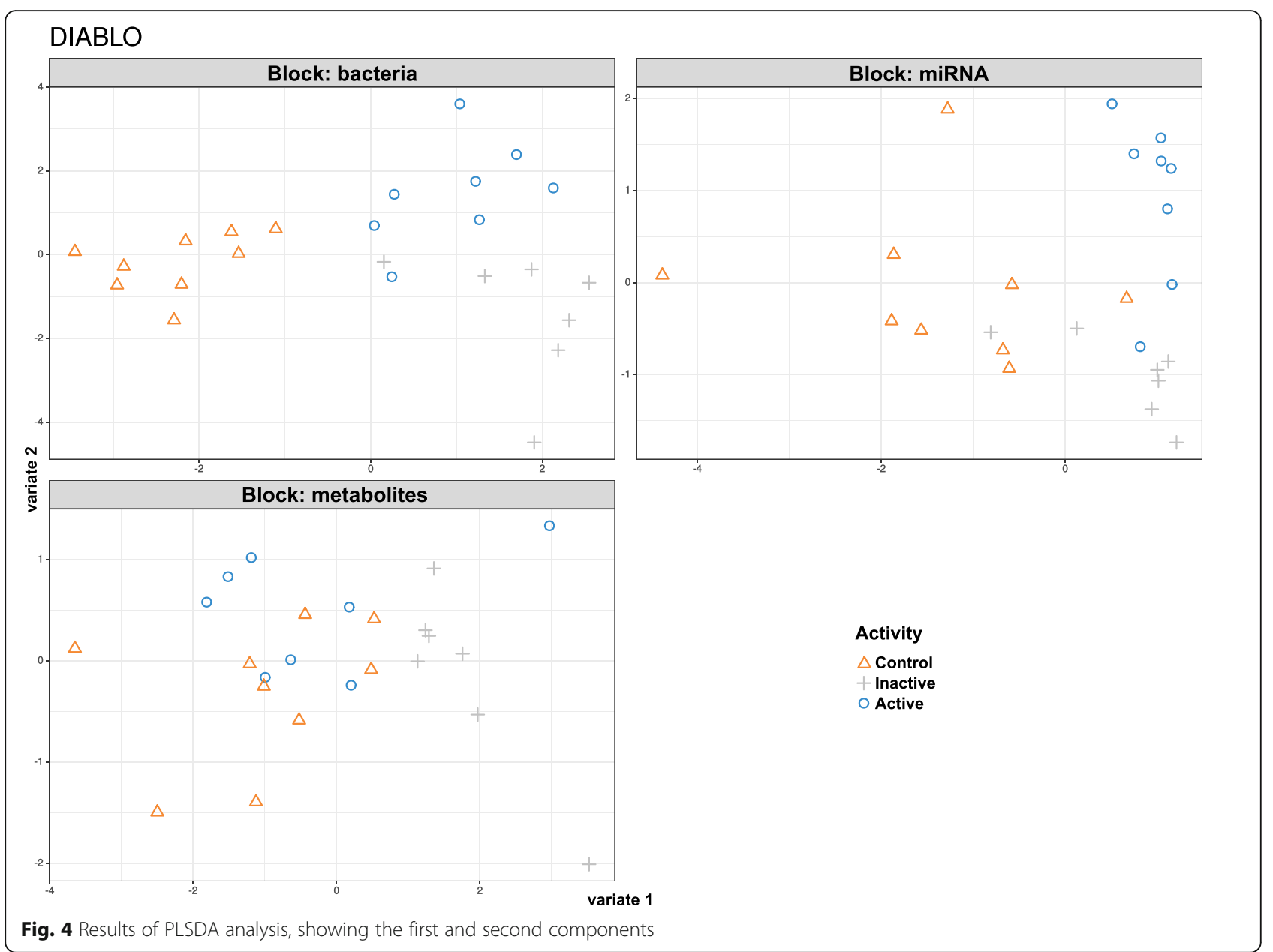

reduces the levels of SCFAs and secondary bile acids, while enhancing the levels of primary bile acids [41].

The best-studied microbial metabolites that influence immune system homeostasis are acetate, butyrate, and propionate [57]. Our SCFA analysis in stool samples showed that the levels of two out of the six SCFAs (butyrate, valerate) were significantly different in between CD patients and controls. Interestingly, four SCFA concentrations were significantly different between $\mathrm{CD}$ patients with inactive and active disease.

Butyrate can act as an energy source for normal colon epithelial cells, promoting their proliferation, but can also inhibit proliferation and induce apoptosis [80, 81]. Butyrate-producing bacteria are depleted in IBD patients, and probiotic treatment with these bacteria has therapeutic potential; supplementation with $F$. prausnitzii and a mix of six butyrate-producers in CD patients increased the butyrate production and reduced acetate levels, and the treatment with B. pullicaecorum 25-3 T and a mixture of six butyrate-producers improved epithelial barrier integrity in vitro [82].
Although modulation of microbiota in IBDs by probiotic butyrate-producing bacteria had little success in controlling the disease [82], transfer of fecal microbiota (FMT) from healthy donors to IBD patients induced a clinical response in $61 \%$ of patients with $C D$ and only $22 \%$ of patients with UC [83, 84]. A higher proportion of Lachnospiraceae in donor stool was associated with a higher success rate of FMT [85], and recipients that responded to FMT exhibited increases in butyrateproducing Lachnospiraceae and Ruminococcaceae [8689].

RNA interference by a single miRNA can regulate multiple genes, whereas a single gene may be targeted by many miRNAs [36]. Three miRNAs (mir-144, mir519, and mir-211) were reported to affect the mucosa in CD [63]. The expression of miR-21 was found to be higher in inflamed colon mucosa of patients with active UC than in controls and UC patients in remission [90], whereas the levels of miR-21 and miR-155 were higher in colon mucosa of UC patients than in controls [91], with these two being among the most frequently and 
consistently deregulated miRNAs in IBD patients [38, 92-94].

Recently published study described 9 miRNAs (miR15a-5p, miR-16-5p, miR-128-3p, miR-142-5p, miR-243p, miR-27a-3p, miR-223-3p, miR-223-5p, miR-3074-5p) and 8 miRNAs (miR-10a-5p, miR-10b-5p, miR-141-3p, miR-192-5p, miR-200a-3p, miR-375, miR-378a-3p, let-7 g-5p) which were significantly increased and decreased, respectively, in stool from $C D$ patients. MiR-192-5p, miR-375, and miR-141-3p correlated with both the clinical $C D$ activity index or $C D$ endoscopic index of severity. The identified fecal miRNA alteration reflected pathophysiological mechanisms in $\mathrm{CD}$, such as Th1 and Th17 inflammation, autophagy, and fibrotic processes [95].

Strong correlations were reported between miR-194$5 \mathrm{p}$ and let-7c-5p and certain bacterial families, such as Enterobacteriaceae [96]. These findings suggest that the intestinal microbiota may alter the profile of fecal miRNAs, which can mediate host-microbiota interactions and regulate intestinal health [36, 96, 97].

Our study identified 13 miRNAs that differed in CD patients and healthy controls. miRNA profiles were distinct in samples from patients with active (12 miRNAs) and inactive (seven miRNAs) CD. After applying multiple test correction, the numbers of miRNAs which remained differential between $C D$ patients and healthy controls and between patients with active $\mathrm{CD}$ and control were reduced to 4 and 3 , respectively. However, although multiple comparisons is typically demanded to minimize false positive results, this approach may also exclude true positive results. Therefore, we decided to present both corrected and uncorrected results, especially when our uncorrected data showed miR-155, miR-223-3p and miR-16-5p which were already reported as altered in IBD patient stool [37, 38]. MiR-223-3p is a pro-inflammatory miRNA, one of the critical components of IL23 inflammatory cascade. It targets claudin- 8 which belongs to protein family responsible for the intestinal barrier homeostasis [98]. miR-16-5p can negatively regulate expression of adenosine receptor A2A and influence the NF- $\mathrm{B} B$ pathway. In turn, dysregulated $N F-\kappa B$ pathway is one of the key elements for CD development and progression [99]. .Furthermore, multiple test correction rejected two upregulated miRNA (miR-1246 and miR-223), reported previously as associating with intestinal inflammation [37, 100]. Of these, miR-1246 may be involved in NFAt proteins activation, which together with the activated NF- $\mathrm{KB}$ pathway may result in the expression of proinflammatory cytokines. MiR-577 and miR-26b-5p, both selected by our uncorrected testing, were found by others as downregulated in active $\mathrm{CD}$ and upregulated in inactive $\mathrm{CD}$, and both were associated with colorectal cancer oncogenesis [101-103].

The correlations between fecal miRNAs and disease activity suggest that the miRNAs may be potential IBD biomarkers [38]. In addition, fecal miRNA levels were found to be associated with microbial composition in a manner that permits the miRNA profile, but not necessarily the microbiota, to indicate the inflammatory potential of the microbiota and its potential to contribute to inflammatory diseases, such as IBD [96]. Conversely, fecal miRNA-mediated inter-species gene regulation may facilitate host control of the gut microbiota [36].

Although microbial abundance may predict metabolite abundance profiles, integrative multi-omics approaches are challenging. Recently, the relationship between microbiota and metabolic changes was investigated using datasets generated under the integrative Human Microbiome Project and mmvec neural network architecture [40]. This study confirmed the core findings of previous investigations [41], including the co-occurrence of Roseburia hominis and multiple carnitines, as well as found a high correlation between Klebsiella spp. and IBD status, and between Klebsiella and several bile acids.

To assess interactions between microbe-metabolitemiRNA abundance, we used another multi-omics integrative method, which included PLSDA computation using the MixOmics [50] package. This method allowed investigation of common information across $16 \mathrm{~S}$ sequencing, miRNA transcriptomic, and SCFA data. The PLSDA-based models using 10 miRNAs, 30 bacterial taxa, and six SCFAs had fairly low error rates for control group discrimination in bacterial component (16\%) and for inactive $\mathrm{CD}$ in metabolite component (4\%). Disappointingly, patients with active disease showed a high level of error for all variables tested. No statistically significant correlations were also uncovered, although 11 pairs presented with high correlation coefficient (absolute value above 0.6). Both of these issues may stem from relatively small sample size which served to generate a large volume of data.

\section{Conclusions}

In summary, we created multi-omics profiles, characterizing the clinical status of $\mathrm{CD}$ patients. Bacterial taxa were the main contributors to the model, with 30 taxa present in the first two principal components, while metabolites achieved low error rates for patients with inactive disease. The main limitations of our study are a relatively small number of patients and, therefore, this preliminary research does not entitle us to draw final conclusions. However, we can speculate that the correlations among the three studied constituents suggest a complex mechanism underlying intestinal immunopathological processes. 


\section{Supplementary information}

Supplementary information accompanies this paper at https://doi.org/10. 1186/s12876-020-01444-3.

Additional file 1: Supplementary Table S1. Taxa differentiating patients with active Crohn's disease from healthy controls. sd - standard deviation, zeroes - number of zeroes in the group, IQR - interquartile range, log2FoldChange - base 2 logarithm from fold-change, stat - Wald's test statistic, pvalue - unadjusted $p$-value, padj - FDR adjusted $\mathrm{p}$-value for most abundant taxa, FC - fold-change, Taxonomy - taxonomic assignment, FisherTest - $p$-value in Fisher's exact test for taxa prevalence, adjustFisher- FDR adjusted $p$-value for Fihser's exact test. Supplementary Table S2. Taxa differentiating patients with inactive Crohn's disease from healthy controls. sd - standard deviation, zeroes - number of zeroes in the group, IQR - interquartile range, log2FoldChange - base 2 logarithm from fold-change, stat - Wald's test statistic, pvalue - unadjusted $p$-value, padj - FDR adjusted p-value for most abundant taxa, FC - fold-change, Taxonomy - taxonomic assignment, FisherTest - p-value in Fisher's exact test for taxa prevalence, adjustFisher- FDR adjusted p-value for Fihser's exact test. Supplementary Table S3. Taxa differentiating patients with inactive Crohn's disease from patients with active disease. sd - standard deviation, zeroes - number of zeroes in the group, IQR - interquartile range, log2FoldChange - base 2 logarithm from fold-change, stat - Wald's test statistic, pvalue - unadjusted p-value, padj - FDR adjusted p-value for most abundant taxa, FC - fold-change, Taxonomy - taxonomic assignment, FisherTest - p-value in Fisher's exact test for taxa prevalence, adjustFisher- FDR adjusted $p$-value for Fihser's exact test. Supplementary Table S4. SCFA log10 conetrations [ppm] for patients with active, inactive CD and control group. Supplementary Table S4. Error rates for PLS-DA models after M fold model vaildation. Supplementary Table S6. Correlation coefficients' values for the relevant variables in the whole dataset, rho - Spearman's correlation coefficient, pvalue - pvalue for the coefficient, padjusted - FDR adjusted pvalue, Taxonomy - taxonomic assignment (if applicable). Supplementary Table SA. GC/MS data.

\section{Additional file $\mathbf{2}$.}

\section{Abbreviations}

SCFA: Short chain fatty acids; miRNA: Micro RNA; CD: Crohn's Disease; IBD: Inflammatory Bowel Disease; CDAl: Crohn Disease Activity Index; GC/ MS: Gas Chromatography - Mass Spectrometry; PLS-DA: Partial Least Squares Discriminant Analysis; StDev: Standard deviation

\section{Acknowledgements}

The authors would like to thank Dr. Michał Mikula for carefully proof-reading the English.

\section{Authors' contributions}

FA, JK - study design; EZ - patient recruitment, sample collection and clinical data preparation; AP, NZ-L - DNA isolation and sequencing; MN, AK Nanostring analysis; FA, JK - GC/MS analysis; MK, FA, JK - data analysis, FA, $\mathrm{JK}, \mathrm{JO}$ - manuscript preparation. FA and JK contributed equally to this study. All authors have read and approved the manuscript.

\section{Funding}

The study was funded by National Science Center [2017/27/B/NZ5/01504] and was supported by the internal grant (GW14JK). The funder had no role in in the study design; in the collection, analysis, and interpretation of the data; in the writing of the report; or in the decision to submit the paper for publication.

\section{Availability of data and materials}

The Metagenomics dataset supporting the conclusions of this article is available in the BioProject repository, https://www.ncbi.nlm.nih.gov/ bioproject/603658

The Nanostring dataset supporting the conclusions of this article is available in the GEO repository, https://www.ncbi.nlm.nih.gov/geo/query/acc.cgi?acc= GSE144535

Mass Spectrometry data showed in supplementary Table SA.

\section{Ethics approval and consent to participate}

All subjects provided written informed consent prior to participation. The study complied with the Declaration of Helsinki and was approved by the ethics committee (decision 54/2017) of the Maria Sklodowska-Curie Institute - Oncology Centre, Warsaw, Poland.

\section{Consent for publication}

Not applicable.

\section{Competing interests}

The authors declare that they have no competing interests.

\section{Author details}

'Department of Genetics, Maria Sklodowska-Curie National Research Institute of Oncology, Roentgena 5, 02-781 Warsaw, Poland. ${ }^{2}$ Department of Gastroenterology, Hepatology and Clinical Oncology, Centre of Postgraduate Medical Education, 02-781 Warsaw, Poland. ${ }^{3}$ Clinical Research Centre, Medical University of Bialystok, Białystok, Poland. ${ }^{4}$ Department of Oncological Gastroenterology, Maria Sklodowska-Curie National Research Institute of Oncology, 02-781 Warsaw, Poland.

Received: 5 February 2020 Accepted: 9 September 2020

Published online: 21 September 2020

\section{References}

1. Qin J, Li R, Raes J, Arumugam M, Burgdorf KS, Manichanh C, et al. A human gut microbial gene catalogue established by metagenomic sequencing. Nature. 2010;464(7285):59-65.

2. Dave M, Higgins PD, Middha S, Rioux KP. The human gut microbiome: current knowledge, challenges, and future directions. Transl Res. 2012;160(4): 246-57

3. $\mathrm{Xu} Z$ Z, Knight R. Dietary effects on human gut microbiome diversity. Br J Nutr. 2015;113(S1):S1-5.

4. Rodrlquez JM, Murphy K, Stanton C, Ross RP, Kober Ol, Juge N, et al. The composition of the gut microbiota throughout life, with an emphasis on early life. Microb Ecol Health Dis. 2015:26(1):26050.

5. Kho ZY, Lal SK. The human gut microbiome - a potential controller of wellness and disease. Front Microbiol. 2018:9:1835.

6. Theilgaard-Mönch K. Gut microbiota sustains hematopoiesis. Blood. 2017; 129(6):662-3.

7. Belkaid Y, Harrison OJ. Homeostatic immunity and the microbiota. Immunity. 2017;46(4):562-76

8. Hand TW, Vujkovic-Cvijin I, Ridaura VK, Belkaid Y. Linking the microbiota, chronic disease, and the immune system. Trends Endocrinol Metab. 2016; 27(12):831-43

9. Wang B, Yao M, Lv L, Ling Z, Li L. The human microbiota in health and disease. Engineering. 2017:3(1):71-82.

10. McGovern DPB, Kugathasan S, Cho JH. Genetics of Inflammatory Bowel Diseases. Gastroenterology. 2015;149(5):1163-1176.e2.

11. Jostins L, Ripke S, Weersma RK, Duerr RH, McGovern DP, Hui KY, et al. Hostmicrobe interactions have shaped the genetic architecture of inflammatory bowel disease. Nature. 2012:491(7422):119-24.

12. Liu JZ, van Sommeren S, Huang H, Ng SC, Alberts R, Takahashi A, et al. Association analyses identify 38 susceptibility loci for inflammatory bowel disease and highlight shared genetic risk across populations. Nat Genet. 2015:47(9):979-86.

13. de Souza HSP, Fiocchi C. Immunopathogenesis of IBD: current state of the art. Nat Rev Gastroenterol Hepatol. 2016;13(1):13-27.

14. Xavier RJ, Podolsky DK. Unravelling the pathogenesis of inflammatory bowe disease. Nature. 2007:448(7152):427-34

15. Morgan XC, Tickle TL, Sokol H, Gevers D, Devaney KL, Ward DV, et al. Dysfunction of the intestinal microbiome in inflammatory bowel disease and treatment. Genome Biol. 2012;13(9):R79.

16. Frank DN, Robertson CE, Hamm CM, Kpadeh Z, Zhang T, Chen H, et al. Disease phenotype and genotype are associated with shifts in intestinalassociated microbiota in inflammatory bowel diseases. Inflamm Bowel Dis 2011:17(1):179-84

17. Darfeuille-Michaud A, Boudeau J, Bulois P, Neut C, Glasser A-L, Barnich N, et al. High prevalence of adherent-invasive Escherichia coli associated with ileal mucosa in Crohn's disease. Gastroenterology. 2004;127(2):412-21. 
18. Palmela C, Chevarin C, Xu Z, Torres J, Sevrin G, Hirten R, et al. Adherentinvasive Escherichia coli in inflammatory bowel disease. Gut. 2018;67(3):57487.

19. Sokol H, Pigneur B, Watterlot L, Lakhdari O, Bermúdez-Humarán LG, Gratadoux J-J, et al. Faecalibacterium prausnitzii is an anti-inflammatory commensal bacterium identified by gut microbiota analysis of Crohn disease patients. Proc Natl Acad Sci U S A. 2008;105(43):16731-6.

20. Quévrain E, Maubert MA, Michon C, Chain F, Marquant R, Tailhades J, et al. Identification of an anti-inflammatory protein from Faecalibacterium prausnitzii, a commensal bacterium deficient in Crohn's disease. Gut. 2016; 65(3):415-25.

21. Arumugam M, Raes J, Pelletier E, Le Paslier D, Yamada T, Mende DR, et al. Enterotypes of the human gut microbiome. Nature. 2011;473(7346):174-80.

22. Louis $P$, Flint HJ. Formation of propionate and butyrate by the human colonic microbiota. Environ Microbiol. 2017:19(1):29-41.

23. Lozupone CA, Stombaugh Jl, Gordon Jl, Jansson JK, Knight R. Diversity, stability and resilience of the human gut microbiota. Nature. 2012;489(7415): 220-30

24. den Besten G, van Eunen K, Groen AK, Venema K, Reijngoud D-J, Bakker BM. The role of short-chain fatty acids in the interplay between diet, gut microbiota, and host energy metabolism. J Lipid Res. 2013;54(9):2325-40.

25. Donohoe DR, Garge N, Zhang X, Sun W, O'Connell TM, Bunger MK, et al. The microbiome and butyrate regulate energy metabolism and autophagy in the mammalian Colon. Cell Metab. 2011;13(5):517-26.

26. Corrêa-Oliveira R, Fachi JL, Vieira A, Sato FT, Vinolo MAR. Regulation of immune cell function by short-chain fatty acids. Clin Transl Immunol. 2016; 5(4):e73.

27. Parada Venegas D, De la Fuente MK, Landskron G, González MJ, Quera R, Dijkstra G, et al. Short Chain fatty acids (SCFAs)-mediated gut epithelial and immune regulation and its relevance for inflammatory bowel diseases. Front Immunol. 2019;10:277.

28. Wang W, Chen L, Zhou R, Wang X, Song L, Huang S, et al. Increased proportions of Bifidobacterium and the Lactobacillus group and loss of butyrate-producing bacteria in inflammatory bowel disease. J Clin Microbiol. 2014;52(2):398-406.

29. Prosberg M, Bendtsen F, Vind I, Petersen AM, Gluud LL. The association between the gut microbiota and the inflammatory bowel disease activity: a systematic review and meta-analysis. Scand J Gastroenterol. 2016;51(12): 1407-15.

30. Ananthakrishnan AN, Khalili H, Konijeti GG, Higuchi LM, de Silva P, Korzenik $J R$, et al. A prospective study of long-term intake of dietary Fiber and risk of Crohn's disease and ulcerative colitis. Gastroenterology. 2013;145(5):970-7.

31. Chiba M. High amount of dietary Fiber not harmful but favorable for Crohn disease. Perm J. 2015;1:58-61.

32. Stein AC, Cohen RD. Dietary Fiber intake and Crohn's disease. Gastroenterology. 2014;146(4):1133.

33. Mehta A, Baltimore D. MicroRNAs as regulatory elements in immune system logic. Nat Rev Immunol. 2016;16(5):279-94.

34. Cao B, Zhou X, Ma J, Zhou W, Yang W, Fan D, et al. Role of MiRNAs in inflammatory bowel disease. Dig Dis Sci. 2017;62(6):1426-38.

35. Ahmed FE, Jeffries CD, Vos PW, Flake G, Nuovo GJ, Sinar DR, et al. Diagnostic MicroRNA markers for screening sporadic human Colon Cancer and active ulcerative colitis in stool and tissue. Cancer Genomics Proteomics. 2009;6(5):281-95.

36. Liu S, da Cunha AP, Rezende RM, Cialic R, Wei Z, Bry L, et al. The host shapes the gut microbiota via fecal MicroRNA. Cell Host Microbe. 2016;19(1):32-43.

37. Verdier J, Breunig IR, Ohse MC, Roubrocks S, Kleinfeld S, Roy S, et al. Faecal micro-RNAs in inflammatory bowel diseases. J Crohns Colitis. 2020;14(1):110-7.

38. Schönauen $K$, Le N, von Arnim U, Schulz C, Malfertheiner P, Link A. Circulating and Fecal microRNAs as Biomarkers for Inflammatory Bowel Diseases. Inflamm Bowel Dis. 2018:24(7):1547-57.

39. Tarazona S, Balzano-Nogueira L, Conesa A. Chapter Eighteen - Multiomics Data Integration in Time Series Experiments. In: Jaumot J, Bedia C, Tauler R, editors. Comprehensive Analytical Chemistry, vol. 82: Elsevier; 2018. p. 50532. (Data Analysis for Omic Sciences: Methods and Applications; vol. 82). [cited 2019 Nov 12]. Available from: http://www.sciencedirect.com/science/ article/pii/S0166526×18300618.

40. Morton JT, Aksenov AA, Nothias LF, Foulds JR, Quinn RA, Badri MH, et al. Learning representations of microbe-metabolite interactions. Nat Methods. 2019:4:1-9.
41. Lloyd-Price J, Arze C, Ananthakrishnan AN, Schirmer M, Avila-Pacheco J, Poon TW, et al. Multi-omics of the gut microbial ecosystem in inflammatory bowel diseases. Nature. 2019;569(7758):655-62.

42. Best WR, Becktel JM, Singleton JW, Kern F. Development of a Crohn's disease activity index: National Cooperative Crohn's disease study. Gastroenterology. 1976;70(3):439-44.

43. Zeber-Lubecka N, Kulecka M, Ambrozkiewicz F, Paziewska A, Lechowicz M Konopka E, et al. Effect of Saccharomyces boulardii and Mode of Delivery on the Early Development of the Gut Microbial Community in Preterm Infants. PLoS ONE. 2016;11(2) [cited 2019 Sep 18]. Available from: https:// www.ncbi.nlm.nih.gov/pmc/articles/PMC4769247/.

44. Takeshi Furuhashi, Genki Ishihara. GC/MS detection of short chain fatty acids from mammalian feces using automated sample preparation in aqueous solution. Application Note, Metabolomics. https://www.agilent.com/cs/ library/applications/59919103EN_Metabolomics_AppNote.pdf.

45. Picard2018toolkit. Broad Institute. http://broadinstitute.github.io/picard/.

46. Schloss PD, Westcott SL, Ryabin T, Hall JR, Hartmann M, Hollister EB, et al. Introducing mothur: open-source, platform-independent, communitysupported software for describing and comparing microbial communities. Appl Environ Microbiol. 2009;75(23):7537-41.

47. Edgar RC, Haas BJ, Clemente JC, Quince C, Knight R. UCHIME improves sensitivity and speed of chimera detection. Bioinformatics. 2011;27(16): 2194-200.

48. Quast C, Pruesse E, Yilmaz P, Gerken J, Schweer T, Yarza P, et al. The SILVA ribosomal RNA gene database project: improved data processing and webbased tools. Nucleic Acids Res. 2013;41(Database issue):D590-6.

49. Love Ml, Huber W, Anders S. Moderated estimation of fold change and dispersion for RNA-seq data with DESeq2. Genome Biol. 2014;15(12):550.

50. Singh A, Shannon CP, Gautier B, Rohart F, Vacher M, Tebbutt SJ, et al. DIABLO: an integrative approach for identifying key molecular drivers from multi-omics assays. Bioinforma Oxf Engl. 2019;35(17):3055-62.

51. Kamada N, Seo S-U, Chen GY, Núñez G. Role of the gut microbiota in immunity and inflammatory disease. Nat Rev Immunol. 2013;13(5):321-35.

52. Clemente JC, Ursell LK, Parfrey LW, Knight R. The impact of the gut microbiota on human health: an integrative view. Cell. 2012;148(6):1258-70.

53. da Fonseca DM, Hand TW, Han S-J, Gerner MY, Zaretsky AG, Byrd AL, et al. Microbiota-dependent Sequelae of acute infection compromise tissuespecific immunity. Cell. 2015;163(2):354-66.

54. Hand TW, Santos LMD, Bouladoux N, Molloy MJ, Pagán AJ, Pepper M, et al. Acute gastrointestinal infection induces long-lived microbiota-specific T cell responses. Science. 2012;337(6101):1553-6.

55. Kamdar K, Khakpour S, Chen J, Leone V, Brulc J, Mangatu T, et al. Genetic and metabolic signals during acute enteric bacterial infection Alter the microbiota and drive progression to chronic inflammatory disease. Cell Host Microbe. 2016;19(1):21-31.

56. Pascal V, Pozuelo M, Borruel N, Casellas F, Campos D, Santiago A, et al. A microbial signature for Crohn's disease. Gut. 2017;66(5):813-22.

57. Gonçalves P, Araújo JR, Di Santo JP. A cross-talk between microbiotaderived short-Chain fatty acids and the host mucosal immune system regulates intestinal homeostasis and inflammatory bowel disease. Inflamm Bowel Dis. 2018;24(3):558-72.

58. Pérez-Brocal V, García-López R, Nos P, Beltrán B, Moret I, Moya A. Metagenomic analysis of Crohn's disease patients identifies changes in the Virome and microbiome related to disease status and therapy, and detects potential interactions and biomarkers. Inflamm Bowel Dis. 2015;21(11):2515-32.

59. Nitzan O, Elias M, Peretz A, Saliba W. Role of antibiotics for treatment of inflammatory bowel disease. World J Gastroenterol. 2016;22(3):1078-87.

60. Bloom SM, Bijanki VN, Nava GM, Sun L, Malvin NP, Donermeyer DL, et al. Commensal Bacteroides species induce colitis in host-genotype-specific fashion in a mouse model of inflammatory bowel disease. Cell Host Microbe. 2011;9(5):390-403.

61. Mottawea W, Chiang C-K, Mühlbauer M, Starr AE, Butcher J, Abujamel T, et al. Altered intestinal microbiota-host mitochondria crosstalk in new onset Crohn's disease. Nat Commun. 2016;7(1):1-14.

62. Fang X, Monk JM, Nurk S, Akseshina M, Zhu Q, Gemmell C, et al. Metagenomics-Based, Strain-Level Analysis of Escherichia coli From a TimeSeries of Microbiome Samples From a Crohn's Disease Patient. Front Microbiol. 2018;9 [cited 2019 Nov 6]. Available from: https://www.frontiersin. org/articles/10.3389/fmicb.2018.02559/full.

63. Rojas-Feria M, Romero-García T, Fernández Caballero-Rico JÁ, Pastor Ramírez $H$, Avilés-Recio M, Castro-Fernandez M, et al. Modulation of faecal 
metagenome in Crohn's disease: role of microRNAs as biomarkers. World Gastroenterol. 2018;24(46):5223-33.

64. Tedjo DI, Smolinska A, Savelkoul PH, Masclee AA, van Schooten FJ, Pierik MJ, et al. The fecal microbiota as a biomarker for disease activity in Crohn's disease. Sci Rep. 2016;6:35216.

65. Gevers D, Kugathasan S, Denson LA, Vázquez-Baeza Y, Van Treuren W, Ren $B$, et al. The treatment-naive microbiome in new-onset Crohn's disease. Cell Host Microbe. 2014;15(3):382-92.

66. Kostic AD, Xavier RJ, Gevers D. The microbiome in inflammatory bowel disease: current status and the future ahead. Gastroenterology. 2014;146(6): 1489-99.

67. Sokol H, Seksik P, Furet JP, Firmesse O, Nion-Larmurier I, Beaugerie L, et al. Low counts of Faecalibacterium prausnitzii in colitis microbiota. Inflamm Bowel Dis. 2009;15(8):1183-9.

68. Verma R, Verma AK, Ahuja V, Paul J. Real-time analysis of mucosal Flora in patients with inflammatory bowel disease in India. J Clin Microbiol. 2010; 48(11):4279-82.

69. Wills ES, Jonkers DMAE, Savelkoul PH, Masclee AA, Pierik MJ, Penders J. Fecal microbial composition of ulcerative colitis and Crohn's disease patients in remission and subsequent exacerbation. PLoS One. 2014;9(3):e90981.

70. Papa E, Docktor M, Smillie C, Weber S, Preheim SP, Gevers D, et al. Noninvasive mapping of the gastrointestinal microbiota identifies children with inflammatory bowel disease. PLoS One. 2012;7(6):e39242.

71. Kumari R, Ahuja V, Paul J. Fluctuations in butyrate-producing bacteria in ulcerative colitis patients of North India. World J Gastroenterol. 2013;19(22): 3404-14.

72. Walker AW, Sanderson JD, Churcher C, Parkes GC, Hudspith BN, Rayment N, et al. High-throughput clone library analysis of the mucosa-associated microbiota reveals dysbiosis and differences between inflamed and noninflamed regions of the intestine in inflammatory bowel disease. BMC Microbiol. 2011;11(1):7.

73. Basset C, Holton J, Bazeos A, Vaira D, Bloom S. Are helicobacter species and Enterotoxigenic Bacteroides fragilis involved in inflammatory bowel disease? Dig Dis Sci. 2004:49(9):1425-32.

74. Prindiville TP, Sheikh RA, Cohen SH, Tang YJ, Cantrell MC, Silva J. Bacteroides fragilis enterotoxin gene sequences in patients with inflammatory bowel disease. Emerg Infect Dis. 2000;6(2):171-4.

75. Ichinohe T, Pang IK, Kumamoto Y, Peaper DR, Ho JH, Murray TS, et al. Microbiota regulates immune defense against respiratory tract influenza a virus infection. Proc Natl Acad Sci. 2011;108(13):5354-9.

76. Abt MC, Osborne LC, Monticelli LA, Doering TA, Alenghat T, Sonnenberg GF, et al. Commensal Bacteria calibrate the activation threshold of innate antiviral immunity. Immunity. 2012;37(1):158-70.

77. Silva JPB, Navegantes-Lima KC, de Oliveira ALB, Rodrigues DVS, Gaspar SLF, Monteiro WS, et al. Protective mechanisms of butyrate on inflammatory bowel disease. Curr Pharm Des. 2019;24(35):4154-66.

78. Kaiko GE, Ryu SH, Koues OI, Collins PL, Solnica-Krezel L, Pearce EJ, et al. The colonic crypt protects stem cells from microbiota-derived metabolites. Cell. 2016;165(7):1708-20

79. Beura LK, Hamilton SE, Bi K, Schenkel JM, Odumade OA, Casey KA, et al. Normalizing the environment recapitulates adult human immune traits in laboratory mice. Nature. 2016;532(7600):512-6.

80. Augenlicht LH, Mariadason JM, Wilson A, Arango D, Yang W, Heerdt BG, et al. Short Chain fatty acids and Colon Cancer. J Nutr. 2002;132(12) 3804S-8S

81. Belcheva A, Irrazabal T, Robertson SJ, Streutker C, Maughan H, Rubino S, et al. Gut microbial metabolism drives transformation of Msh2-deficient Colon epithelial cells. Cell. 2014;158(2):288-99.

82. Geirnaert A, Calatayud M, Grootaert C, Laukens D, Devriese S, Smagghe G, et al. Butyrate-producing bacteria supplemented in vitro to Crohn's disease patient microbiota increased butyrate production and enhanced intestinal epithelial barrier integrity. Sci Rep. 2017;7(1):1-14.

83. Gupta S, Allen-Vercoe E, Petrof EO. Fecal microbiota transplantation: in perspective. Ther Adv Gastroenterol. 2016;9(2):229-39.

84. Colman RJ, Rubin DT. Fecal microbiota transplantation as therapy for inflammatory bowel disease: a systematic review and meta-analysis. J Crohns Colitis. 2014;8(12):1569-81.

85. Moayyedi P, Surette MG, Kim PT, Libertucci J, Wolfe M, Onischi C, et al. Fecal Microbiota Transplantation Induces Remission in Patients With Active Ulcerative Colitis in a Randomized Controlled Trial. Gastroenterology. 2015; 149(1):102-109.e6.
86. Angelberger S, Reinisch W, Makristathis A, Lichtenberger C, Dejaco C, Papay $P$, et al. Temporal bacterial community dynamics vary among ulcerative colitis patients after fecal microbiota transplantation. Am J Gastroenterol. 2013;108(10):1620-30.

87. Paramsothy S, Kamm MA, Kaakoush NO, Walsh AJ, van den Bogaerde J, Samuel D, et al. Multidonor intensive faecal microbiota transplantation for active ulcerative colitis: a randomised placebo-controlled trial. Lancet. 2017; 389(10075):1218-28.

88. Vermeire S, Joossens M, Verbeke K, Wang J, Machiels K, Sabino J, et al. Donor species richness determines Faecal microbiota transplantation success in inflammatory bowel disease. J Crohns Colitis. 2016;10(4):387-94.

89. Vaughn BP, Vatanen T, Allegretti JR, Bai A, Xavier RJ, Korzenik J, et al. Increased intestinal microbial diversity following fecal microbiota transplant for active Crohn's disease. Inflamm Bowel Dis. 2016;22(9):2182-90.

90. Wu F, Zikusoka M, Trindade A, Dassopoulos T, Harris ML, Bayless TM, et al. MicroRNAs Are Differentially Expressed in Ulcerative Colitis and Alter Expression of Macrophage Inflammatory Peptide-2a. Gastroenterology. 2008;135(5):1624-1635.e24.

91. Takagi T, Naito Y, Mizushima K, Hirata I, Yagi N, Tomatsuri N, et al. Increased expression of microRNA in the inflamed colonic mucosa of patients with active ulcerative colitis. J Gastroenterol Hepatol. 2010;25(s1):S129-33.

92. Archanioti P, Gazouli M, Theodoropoulos G, Vaiopoulou A, Nikiteas N. MicroRNAs as regulators and possible diagnostic bio-markers in inflammatory bowel disease. J Crohns Colitis. 2011;5(6):520-4.

93. Kalla R, Ventham NT, Kennedy NA, Quintana JF, Nimmo ER, Buck AH, et al. MicroRNAs: new players in IBD. Gut. 2015;64(3):504-13.

94. Paraskevi A, Theodoropoulos G, Papaconstantinou I, Mantzaris G, Nikiteas N, Gazouli M. Circulating MicroRNA in inflammatory bowel disease. J Crohns Colitis. 2012;6(9):900-4

95. Wohnhaas CT, Schmid R, Rolser M, Kaaru E, Langgartner D, Rieber K, et al. Fecal MicroRNAs Show Promise as Noninvasive Crohn's Disease Biomarkers. Crohns Colitis 360. 2020;2(1):otaa003.

96. Viennois E, Chassaing B, Tahsin A, Pujada A, Wang L, Gewirtz AT, et al. Hostderived fecal microRNAs can indicate gut microbiota healthiness and ability to induce inflammation. Theranostics. 2019;9(15):4542-57.

97. Dalmasso G, Nguyen HTT, Yan Y, Laroui H, Charania MA, Ayyadurai S, et al. Microbiota Modulate Host Gene Expression via MicroRNAs. PLoS One. 2011; 6(4):e19293

98. Wang H, Chao K, Ng SC, Bai AH, Yu Q, Yu J, et al. Pro-inflammatory miR-223 mediates the cross-talk between the IL23 pathway and the intestinal barrier in inflammatory bowel disease. Genome Biol. 2016;17(1):58.

99. Tian T, Zhou Y, Feng X, Ye S, Wang H, Wu W, et al. MicroRNA-16 is putatively involved in the NF-KB pathway regulation in ulcerative colitis through adenosine A2a receptor (A2aAR) mRNA targeting. Sci Rep. 2016; 6(1):30824.

100. Ji Y, Li X, Zhu Y, Li N, Zhang N, Niu M. Faecal microRNA as a biomarker of the activity and prognosis of inflammatory bowel diseases. Biochem Biophys Res Commun. 2018;503(4):2443-50.

101. Jiang $H$, Ju H, Zhang $L$, Lu H, Jie K. microRNA-577 suppresses tumor growth and enhances chemosensitivity in colorectal cancer. J Biochem Mol Toxicol. 2017;31(6):e21888

102. Li Y, Sun Z, Liu B, Shan Y, Zhao L, Jia L. Tumor-suppressive miR-26a and miR-26b inhibit cell aggressiveness by regulating FUT4 in colorectal cancer. Cell Death Dis. 2017;8(6):e2892.

103. Ding $L$, Lan Z, Xiong $X, A o H$, Feng $Y, G u H$, et al. The dual role of MicroRNAs in colorectal Cancer progression. Int J Mol Sci. 2018;19(9):2791.

\section{Publisher's Note}

Springer Nature remains neutral with regard to jurisdictional claims in published maps and institutional affiliations. 